\title{
Learning in the New Hybrid Model of Education: Understanding the Emotional Intelligence of the UPHSD Calamba Students in the New Normal
}

\author{
Arianne Kate M. Lansigan \\ University of Perpetual Help System DALTA Calamba \\ \{yanlansigan@gmail.com\}
}

\begin{abstract}
The new normal for education has been greatly affected by the current situation worldwide. It has opened varieties of distance learning strategies and continuous development in education in terms of technology, approach, and uses. Emotional Intelligence has become an important factor in the traditional learning environment. Thus, with the current set up we can determine and examine the importance of EI as an important determinant for the readiness and acceptance of the students. The goal of this study is to explore and understand the EI of the selected students and see the relation and impact of the new mode of learning. Semi-structured survey was collected and recorded for analysis. The result of this study refers to the consideration of the occurrence of EI and its component in achieving a successful learning environment and teaching strategy.
\end{abstract}

Keywords: Emotional Intelligence, Distance Learning, Education, Online Education

\section{Introduction}

The current pandemic has greatly affected the daily lives of people around the world. It brought a lot of drastic changes and effects in a different situation. As of November 2020, there are almost 60,000,000 confirmed cases of COVID-19 according to the official website of Department of Health. The rising cases urged the government and public to strategize their daily activities, thus, the education system. It created different structures for education to continue in parting information and create students to be prepared for their fields.

According to Arkorful and Abaidoo in 2014, it is difficult to identify a common definition for e-learning. Some of the authors refer to e-learning as providing complete on-line courses only whereas comprise web-supplemented and web-dependent services for the provision of educational and support processes. In this study, we will define online education in the idea of the 'new normal'. The definition of new normal teaching is referred to as both blended and hybrid learning. If we will look into deeper understanding it is closely related to blended learning which is, with little or no difference in the meaning of the terms among most educators - in general terms, blended learning combines online delivery of educational content with the best features of classroom interaction and lives instruction to personalize learning, 
allow thoughtful reflection, and differentiate instruction from student to student across a diverse group of learners (Watson, 2008).

The University of Perpetual Help System DALTA Calamba embraced the 'new normal' after the College of Higher Education (CHED) announced that face-to-face classes will not be allowed for the school year 2020-2021 as stated in CNN News(CHED: No more face-to-face classes for colleges, universities using new school calendar as COVID-19 crisis continues (cnnphilippines.com). UPHSD Calamba practices online flexible learning for students to continue classes conducted through an online platform. Enrolled students in UPHSD Calamba are given Microsoft Teams and Learning Management System (LMS) accounts which give them access to school modules and video call for synchronous classes. The administration, faculty, and students have been practicing how to adjust to the new normal system in terms of teaching, deadlines, submission, and communication with the students. The school has been very supportive in conducting surveys, updates, and support both for the faculty and the students. The university conducts synchronous and asynchronous classes to practice balance understanding and to give equal opportunities for students and faculty in creating a lenient class for every student.

In the past decade, online learning has become an increasingly important component of education. The growth of online education created opportunities and limitations. The pandemic and the changes in education have been affecting the students in terms of handling and balancing different situations. The deviation from face-to-face to online class brought different expectations and drought both for the student and the faculty. The effects directed not only the modification from $\mathrm{f} 2 \mathrm{f}$ to online class but also their psychological state. One of the greatest factors affected in learning is the students' Emotional quotient or EQ; the ability to understand, use, and manage your own emotions in positive ways to relieve stress, communicate effectively, empathize with others, overcome challenges and defuse conflict. EQ or EI not only satisfies the understanding that there is a relation between our emotions and understanding, hence, but it also says that having IQ and EQ are the most effective tandem to learn and comprehend ideas.

\subsection{Statement of the Problem}

The purpose of this study to recognize the presence of emotional intelligence in the 'new normal' setup of education of the UPHSD Calamba college students. Specifically, the study aims to:

a. Identify the students' understanding of their emotional intelligence while engaging in the online education;

b. Describe the change in EI from face to face to 'new normal, and

c. (Based on the findings of the study) Determine a EI guide for college students.

\subsection{Conceptual Framework}




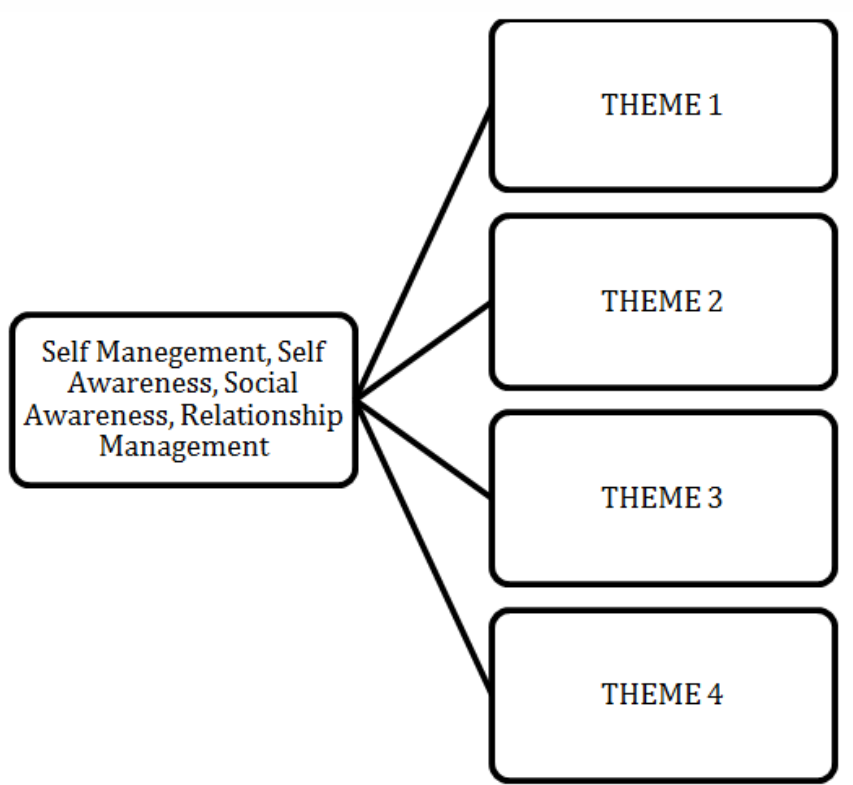

Fig 1. Conceptual Framework

The researcher came up with this framework which is based on the framework analysis method wherein you should come up with themes after being familiarize with the concepts or ideas. The four (4) attributes of Emotional Intelligence was included in the first box to give an idea that the themes will be based on this attributes which leads to the EI of the respondents. According to Goleman (1997), -Goleman's Model, there are four components of Emotional Intelligence: (a) Self- Awareness, (b) Social Awareness, (c) Self-Management, (d) Social Skills. As defined in the model,

a. Self-Awareness means being aware of your own emotions, and being able to identify them correctly. As students, they should recognize their strengths and weaknesses. In this study, the students should describe their awareness of their feelings which causes them to be happy, satisfied, proud, irritated, etc with their academic performance or output.

b. Self-Management is the ability to control your emotional reactions while still behaving with honesty and integrity. Having EI under self-management discusses that you can handle your behavior and/or be calm without hurting others. The respondents of the study should discuss how they were able to manage their feelings or moods by setting it aside and how they explain to others when they do not feel good about something.

c. Social awareness is about spreading your emotional attention to those around you. This is the opposite of self-awareness. Respondents should declare their acceptance of the people around them. Given the current situation of online classes, the students discussed the absence or presence of social awareness.

d. Relationship Management is about how you embrace yourself and other emotions to reach a certain goal. The previous attributes contribute to relationship management. Having the three attributes mentioned above gives a conclusion on how you handle conversation, argument, or even friendship. In this study, it discusses the idea of the relationship having the absence of face-to-face communication. 
The study used the four attributes as it is used in a successful or strong Emotional Intelligence in one person. Mayer, Salovey, and Caruso (2004) developed the four-branch ability model of EI. They suggest that the abilities and skills of EI can be divided into 4 areas - the ability to: (1)Perceive emotion; (2)Use emotion to facilitate thought; (3)Understand emotions; and (4) Manage emotion. However, the stated abilities were encored in the four attributes of Goleman. It also differs the idea of information processing or intelligence creation which fits to one's overall personality. According to Boyatzis, Goleman, and Rhee (2000), Goleman reduced the number of skills to twenty under the 4 general attributes. The skills:

a. Self-awareness: Awareness of one's emotions, Accurate self-assessment, and Selfconfidence.

b. Self-management: Emotional self-control, Transparency, Adaptability, Orientation of efforts, Initiative, and Optimism.

c. Social awareness: Empathy, Organizational awareness, and Orientation of services

d. Relationship management: Managing others, Inspired leadership, Influence, Conflict management, Teamwork and collaboration

\subsection{Scope and Limitation}

The study only focused on emotional intelligence and did not touch the notion of Intelligence Quotient (IQ). Though the two entities are related, EQ cover different aspect as to IQ. The researcher portrayed only evidence related to emotions, understanding, experience, opinion, and relation to EQ. This study contributed only to the four (4) attributes and removed Goleman's fifth attribute to further scrutinize the topic and characterized only related topics for students; thus the respondents. The researchers gathered information from the UPHSD Calamba College students due to low awareness of emotional intelligence which can greatly help their academic performance. However, with the current situation, the researcher focused on the idea that there could be possible differences or discoveries in EI.

\section{Research Methodology}

\subsection{Research Design}

This study will use a qualitative research approach using the framework analysis method utilizing the phenomenological approach. The study relies on interpretative data to describe the variables being, explored. In the study Qualitative Research Designs: A Conceptual Framework by Astalin in 2013, he defined Phenomena may be events, situations, experiences or concepts, thus, phenomenology is a way of describing something that exists as an integral part of the world in which we are living.

\subsection{Population of the study}

The study will focus on the enrolled College students of UPHSD Calamba. The researcher selected four (4) college students from each College Department- a total of 48 respondents who are qualified given the following criteria: 
Table 1. Qualification of Participants

1. Bonafide students of UPHSD Calamba

Qualifications of participants

2. Enrolled for full time load

3. Enrolled in the Online Education Set up

4. Has experienced face-to-face classroom set up (preferably 2nd year to higher years of

College)

5. Aware of his/her emotional intelligence (pre-interview and surveyed)

Table 2. List of UPHSD Calamba College Department

DEPARTMENT

NO OF STUDENTS

\begin{tabular}{lc}
\hline College of Arts, Sciences, and Education & 4 \\
College of Criminology & 4 \\
College of Computer Studies & 4 \\
College of Architecture & 4 \\
College of Engineering & 4 \\
College of Radiologic Technology & 4 \\
College of Physical Therapy & 4 \\
College of Business and Accountancy & 4 \\
College of International Hospitality Management & 4 \\
College of Nursing & 4 \\
College of Pharmacy & 4 \\
College of Medical Technology & 4 \\
\hline
\end{tabular}

Based on the distribution of respondents and recommendation from the college, the researcher gathered data from 48 students from each College department. The respondents will undergo a recorded online interview using an online platform (Zoom, Facebook Messenger, MS Teams) given permission supported with their signature and acknowledgment. This study focused on 48 students to satisfy the stability of information considering that they have different levels, experiences, exposure, and understanding.

\subsection{Research Instrument}

The researcher used interview questions and conducted a focus group discussion through Zoom/Teams (recorded for validation purposes only). This study focused on these two instruments to form themes that can be interpreted in the findings. There are a total of 20 questions based on the four (4) attributes of Emotional Intelligence.

\subsection{Data Gathering Procedure}

This study used the FGD method for time management and an effective way of identifying experience differences and a variety of responses. The researcher prepared a letter of requests for student participation approved by the college deans, research head, and school director. The respondents also signed a waiver for Data Privacy Act agreement and clarification of data interpretation. Before the FGD and classification of respondents, several students were handed survey/interview forms to gather information about their awareness of their emotional intelligence. After the collection of data, the responses were duly encoded and interpreted for theme and sub-themes identification. The FGD was transcribed and validated for record purposes. The respondents were informed about their answers and duly signed a waiver for 
permission on posting and quoting in the study. The names were not exposed rather the students were named Student 1,2,3 and so on to give them privacy and not be used for future references.

\section{Findings of the Study}

The Mixed Model of Emotional Intelligence by Daniel Goleman is the most widely used model of EI. It is accepted in different situations due to its variety of explanation and discussion on self and relationship management. This model involves a range of competencies and these are divided into skill sets and which form the picture of an individual's level of emotional intelligence (Kapur, 2018). The researcher focused on the four attributes due to its relation to the data gathered from respondents. The importance of Emotional Intelligence in academics is the creation of the impact of social behavior in school which can lead to; relations with peers, faculty, and school administrators. The description of EI in education can also give clarity on oneness and team performance of the students. EI is important for developing friendships during childhood and that because difficulties with peers early on in life can have consequences for later adjustment, suggest that low EI may be a developmental risk factor for a host of problem behaviors. EI of children and youth tend to focus on two related questions: the relationship between EI and academic achievement and the association between EI and a range of variables measuring adjustment (or maladjustment) in the school environment. (Collin, Parker, et.al, 2009). Through FGD and interpretation of transcription, the researcher focused on four (4) themes evident and occurring mostly in the data provided by the respondents.

\subsection{Uncertainty}

Uncertainty refers to the state of an organism that lacks information about whether, where, when, how, or why an event has occurred or will occur (Bar-Ana, Gilbert, et.al, 2009). While the students are gaining information and learnings from their subjects despite the condition, they tend to expect their performance in class.

Student 12: " Minsan po, hindi na ako sigurado if dapat ba akong nag-enroll ngayong semester.. uhm, kasi ang hirap po ng gusto kong maging focus pero hindi po ako motivated or sure kung gusto ko pa ba mag-aral." . Their skills in their own abilities and having selfconfidence looses its importance specifically in self-awareness. The respondents agreed on having the same emotions or feelings in line to understanding their assurance in attending classes or submitting their school load. Student 7: "Same po ako ni (student D), every time I will submit my exam or assignment, I do not feel that I did it right, kasi wala po akong pwedeng pagtanungan kung hindi sarili ko. Respondents mentioned that there are a lot of times that they do not feel confident in answering their exercises in their subject because they feel clueless about the topic. Their answers involved the idea of their lack of capability to adapt, control themselves in questioning their works or even care about assessing their actions towards their output which results to failing grades or sometimes absences in class.

The concept of responsibility was also apparent in the transcription as they have mentioned similarities in defining responsibility in online classes. Student 5, "Opo... I want to be responsible po sana in my emotions and actions kapag may ginagawa ako sa school and towards sa family ko or friends, pero dahil sa maraming factors, hindi ko napapansin na minsan fluctuating talaga ung moods ko". The significance of responsibility in education is 
important since it holds the essence of learning and acquiring knowledge for a student to perform well. In this study, the respondents clearly stated different situation about responsibility. With the current situation, their form of responsibility in family, school, or peers is not balance and inconsistent. Student 22, "My emotions during this pandemic messed up my excitement sa school kasi wala na akong nakikitang friends or teachers namin, parang kulang yung ma-feel ko na ako lang".

\subsection{Self- reliance and Social Intelligence}

In this study, the respondents were very clear on reiterating the importance of team work and independence. According to Psyhcology, self-reliance has strong theoretical significance thanks to its implications for happiness. Student 17, "Kapag kasama ko mga kaibigan ko parang ang dali gumawa, siguro kasi pwede magkopyahan, pero mas marami yung tulungan, sa three (3) years ko dito sa Perpetual, nasanay akong may kasama ako mag-aral, nung (noong) nag online class, ako lang mag-isa kasi hindi ko sila maabala siyempre". Because of their common background, preferences and application on different activities, the students mentioned that they can focus more on their studies if they are accompanied by their classmates or peers due to empathy, understanding and relationship which they built in school. In online education, they could not freely express their emotions towards their teachers or their classmates because of certain restrictions; technology, noise in communication process, misinterpretation, absence of physical touch.

Student 1, "Ako po to be honest, mas naramdaman ko na ang dami ko pa lang magagawa kapag mag-isa lang ako, hindi naman po sa ayaw ko makita or makasama ang classmates ko, iba pa rin kapag makakusap ko directly lalo na teacher ko, pero dahil ngayon mag-isa lang ako, mas nagging responsible ako sa pag-create ng idea and ang result non sakin, mas tumaas yung tiwala ko sa sarili ko." Respondents explain that their individual performance abled them to measure their EI through their reactions towards different situation in class; submission before the deadline, making projects on their own, asking help from their family instead of peers - "noong isang araw, nagulat na lang ako na tinutulungan ako ng nanay ko, parang first time ko humingi ng tulong sa family ko na related sa acads ko" .

During the FGD, one of the respondents mentioned that she actually felt the need to understand the situation of their teachers and the other students. "During the online classes, ang daming beses na nawawala yung iba kong classmates, tapos nalalaman naming na nawalan ng internet or data, so sa group chat naming, as much as possible, tulungan sa assignment, or pag catch-up sa lessons". In terms of social awareness, the respondents mentioned the formation of a relationship with their peers having diverse backgrounds, experiences, or preferences. They were able to organize their class and department because of the pressure of online classes.

\subsection{Opportunities and Social Skills enhancement}

The absence of physical interaction in online education surprisingly possessed social skills during these times. The students created skills on how they can help, influence, negotiate, or even develop personality which greatly contributes to social relationships. "I was able to understand the importance of hearing someone who we can follow, compared to normal class, sa online set up, wala kaming pwedeng balikan unless makausap si teacher through chat, which is rare.", as stated by Student 20. However, it formed bond and relationship with their 
family. The respondents look for different provisions to help them in their academics, and of course their family was the majority of their answers.

Table 3. Themes created in the data: Emotional Intelligence FGD with UPHSD Calamba students

\begin{tabular}{lccc}
\hline \multicolumn{1}{c}{ Uncertainty } & Self-reliance & Social Intelligence & Opportunities \\
\hline Great impact on mental state & $\begin{array}{c}\text { Individual Work/Group } \\
\text { System appreciation } \\
\text { Relationship with self } \\
\text { No self confidence }\end{array}$ & Dependency & $\begin{array}{c}\text { Personal } \\
\text { Growth } \\
\text { Relationship } \\
\text { with Family }\end{array}$ \\
Sense of Responsibility & Empathy & Independence \\
Enthusiasm towards academics & & & Social Pressure \\
\hline
\end{tabular}

\section{Conclusion}

The role of Emotional Intelligence in online education has enticed the interest of the researchers and the university. Expressing and managing emotions have been very sensitive especially these times. The increasing number of suicide and breakdown from the faculty and students is a challenge for universities and school administrators to study the balance life and studies of the students. It is therefore important to analyze the situation based on the responses from this study. Universities should build sustainable bridge for the students to feel important or empathized. The respondents are aware of their EIs; and they stated the gap in it while in online setup and the difference in face to face classes. Regarding the implications of these findings, this study evidently created the idea that students manage their EI highly but the situation and some constraints coming from the online set up of learning disrupts them in developing it. Finally, these instruments can improve quality education in times of pandemic and future challenges.

\section{References}

[1] Arkorful, Valentina (2014). The role of e-learning, the advantages and disadvantages of its adoption in Higher Education. International Journal of Education and Research. Vol. 2 No. 12 Decelmber 2014. Retrieved from 34.pdf (ijern.com)

[2] Carmeli, A., \& Josman, Z. E. (2006). The relationship among emotional intelligence, task performance, and organizational citizenship behaviors. Human Performance, 19, 403-419

[3] Goleman, D. (1997). Emotional Intelligence: Why It Can Matter More Than IQ. Ljubljana: Mladinska knjiga.

[4] Goldstein, S. (2017, September 26). EQ is massively more important than IQ for leaders. Here's why. Retrieved November 30, 2020, from Inc.: www.inc.com/stevegoldstein/qu-is-massively-more-important-than-iq-for-leaders-heres-why.html

[5] Kang, S. (2014). The self-motivated kid: How to raise happy, healthy children who know what they want and go after it. New York, New York, USA: Penguin Random House

[6] Shapiro SL, Shapiro DE, Schwartz ER. Stress management in medical education: A review of the literature. Acad Med. 2000;75:748759. http://journals.lww.com/academicmedicine/Fulltext/2000/07000/Stress_Managem ent_in_Medical_Education_A_Review.23.aspx. Accessed December 1, 2020 
[7] Frameworks for Qualitative Research. Retrieved from: 13887_Chapter5.pdf (sagepub.com), December 2, 2020. 